\title{
The impact of Regional co-payment and National reimbursement criteria on statins use in Italy: an interrupted time-series analysis
}

Gianfranco Damiani ${ }^{1 *}$, Bruno Federico ${ }^{2}$, Angela Anselmi ${ }^{1}$, Caterina Bianca Neve Aurora Bianchi ${ }^{1}$, Giulia Silvestrini ${ }^{1}$, Lanfranco lodice ${ }^{1}$, Pierluigi Navarra ${ }^{3}$, Roberto Da Cas $^{4}$, Roberto Raschetti ${ }^{4}$ and Walter Ricciardi ${ }^{1}$

\begin{abstract}
Background: Statins are among the most commonly prescribed drugs worldwide in the prevention of cardiovascular diseases and their effectiveness is largely acknowledged. The consumption of statins increased four-fold during the 2000-2010 decade in Italy and national and regional control policies were developed. Restrictions to reimbursement were fixed at the national level, whereas co-payment was introduced in some, but not all, regions. The aim of the present study is to assess the impact of such policies on the consumption of statins in Italy between 2001-2007 among outpatients.
\end{abstract}

Methods: The statin use was measured in terms of defined daily doses per 1,000 inhabitants per day (DDD/1000 inh. day) from May 2001 to December 2007. The study was conducted in 17 out of 21 regions, nine of which had implemented a co-payment policy. Time trends in consumption before and after the introduction of co-payment policies and reimbursement criteria were examined using segmented regression analysis of interrupted time-series, adjusting for seasonal components.

Results: The consumption of statins increased by 22.9 DDD/1000 inh. day in May 2001 to 54.7 DDD/1000 inh. day in December 2007. On average, there was a 1.7\% increase in statin use each month before the national guideline changed while the increase was about $0.5 \%$ afterwards. The revision of the reimbursement criteria was associated with a significant decrease in level (coefficient $=-2.80,95 \% \mathrm{Cl}-3.70$ to $-1.90 \mathrm{p}$-value $<0.001$ ) and trend (coefficient $=-0.33,95 \% \mathrm{Cl}-0.37$ to $-0.29 \mathrm{p}$-value $<0.001$ ). The introduction of co-payment was associated with a significant change in trend of consumption so that the overall use of the drug increased by $0.04(95 \% \mathrm{Cl} 0.02$ to 0.07, p-value < 0.001) DDD/1000 inh. day per month in the post-intervention period, but there was no evidence of a change in level of consumption ( $p$-value $=0.163$ ).

Conclusions: Consumption of statins in Italy increased almost three-fold during the study period. The restriction to reimbursement Interventions was associated with an immediate drop and a decrease in trend of statin use, while the regional copayment was associated with a small increase in trend of statin use.

Keywords: Interrupted time-series, Statin use, Pharmaceutical policy, Italy

\footnotetext{
* Correspondence: gdamiani@rm.unicatt.it

'Department of Public Health, Catholic University of the Sacred Heart, Rome, Italy

Full list of author information is available at the end of the article
} 


\section{Background}

In recent years, many policies have been implemented across the European Union to enhance the appropriate use of drugs and to contain pharmaceutical cost $[1,2]$.

The 3-hydroxy-3-methylglutaryl coenzyme A (HMGCoA) reductase inhibitors (statins) were first used in patients with myocardial infarction (MI) and hypercholesterolemia. Several clinical trials, cohort studies and reviews largely acknowledged statins effectiveness: their beneficial effects were evident as lipid-lowering agents in patients with ischemic heart disease (IHD), other atherosclerotic cardiovascular diseases (CVD), diabetes, and even in the treatment of asymptomatic individuals [3-12]. These clinical trials had major implications for cholesterol management that resulted in an increase in the number of patients for whom statins may be considered clinically appropriate [13], such raising the expenditure, at least before the patent expiration of some molecules.

Thus, a wide range of measures to contain the cost of statins was developed in many Countries (e.g. Norway), including lists of preferred generic substitutions and/or medicines for which the patients are reimbursed (Austria and Finland), and co-payment policies (USA, Canada). The effect of these policies was assessed in recent studies with regards to drug expenditure, adherence therapy, or health outcomes [14-19].

Even though Italy has one of the lowest rates of use in Europe [20], the consumption of statins has constantly increased during the last decade, almost quadrupling its level from 14.67 DDD/1000 inhabitants per day (DDD/ 1000 inh. day) in 2000 to $51.70 \mathrm{DDD} / 1000 \mathrm{inh}$. day in 2010 [21,22]. Compared to 2010, in 2011 (the latest available data for a whole year) statin consumption still increased $(+7.7 \%)$ while the expenditure decreased $(-13.1 \%)$ Despite this fact, statins rank first in expenditure as a cardiovascular drug subgroup [23].

Most of the costs are charged to the Italian National Health Service (Servizio Sanitario Nazionale, SSN) which provides universal coverage.

In order to contain the cost of drugs, a co-payment policy was first introduced in Italy in 1978, then abolished in January 2001 by the national government, and subsequently it was reintroduced at the local level by some regions, following the decentralization trend [24] of the policy-making government.

The change in Italian Constitutional Chart in 2001, determined a devolution process that transferred legislative, administrative and considerable fiscal powers to regions. According to this, the central government was granted the exclusive power to set "essential levels of care" (Livelli Essenziali di Assistenza, LEAs), a package of benefits that are publicly funded and must be guaranteed to all citizens in all regions. Most essential drugs are included in LEAs. At the same time, regions have almost full control over the provision of services, regulation, and funding with the mandate to provide LEAs [25]. LEAs hold regions accountable to national standards.

Thus, since 2002, regions have made different choices regarding co-payment policies with subsequent significant cross-regional variation among patient charges for drugs [26]. In regions with a co-payment policy, patients are required to contribute to the cost of pharmaceuticals by a fixed amount per prescription, ranging from 1 to 5 euros, depending on the region [27]. On the other hand, the criteria for the reimbursement of statins were issued and periodically revised at the national level. They contained specific indications, inspired by clinical practice and guidelines, that determined whether the statins could be prescribed and reimbursed for specific diseases and conditions [28]. Their introduction had a dual purpose: cost containment and a more appropriate use of these drugs [29]. In November 2004, according to new scientific evidence, criteria for reimbursement for lipid lowering agents were revised by the new Italian Drug Agency (AIFA). The new criteria (Nota AIFA 13) restricted statin reimbursement to high risk users, based on a national risk profile for primary CVD prevention while they extended reimbursement for patients with diabetes in secondary CVD prevention [30,31].

The aim of this study was to evaluate the impact of the national and regional cost containment measures on statin use in Italy during the period May 2001 - December 2007.

\section{Methods}

Data

Data on drug consumption in Italy between May 1, 2001 and December 31, 2007 were collected from the Federfarma database. This database includes all drug use paid by the National Health Service, excluding inhospital as well as out-of-pocket drug use. Data were provided by the Italian National Institute of Health on an aggregate basis, with regions and time being the unit of analysis. Because no individual data was available, ethical approval of the study was not sought.

The dataset included the number of Defined Daily Doses per 1000 inhabitants per day (DDD/1000 inh. day) for all drugs in the C10AAxx category of the Anatomical Therapeutic Chemical (ATC) system [32]. Data from each Italian region were available on a monthly basis, and they were adjusted by age and sex according to the weights established by the Department of Programming of the Italian Ministry of Health.

The analysis considered 17 out of the 21 Italian regions. They were divided in two groups. The first one included regions which (re)introduced a co-payment: Bolzano, Campania, Liguria, Lombardia, Molise, Piemonte, 
Puglia, Sicilia and Veneto. The second one included those regions that did not reintroduce a co-payment: Basilicata, Emilia Romagna, Friuli Venezia Giulia, Marche, Toscana, Trento, Umbria, Valle d'Aosta. We excluded Abruzzo, Calabria, Lazio and Sardegna because these regions modified the co-payment mechanism several times during the study period.

\section{Statistical analysis}

A descriptive analysis of the consumption of statins during the study period was first performed. Tables describing the consumption of statins for both regions with and without co-payment policies have been compiled. An average monthly variation index (calculated as: [(End-period consumption/Start-period consumption) $\left.)^{1 / n}-1\right]^{* 100)}$ was provided for both the periods pre- and post- prescribing guideline change. Graphs showing the statins use trends for both regions with and without co-payment policies were plotted. Subsequently, we analysed the series to identify the most appropriate model to describe the data until the time of intervention, and to make a forecast for the post-intervention period in order to asses if there was a significant impact of the policy change on the consumption of statins. We chose the most befitting model (between the ARIMA and the exponential smoothing models) after a residual analysis through the Ljung-Box test [33] and the check of the autocorrelation and partial autocorrelation functions of the residual. The mean absolute error (MAE) and the mean absolute percentage error (MAPE) between the observed and the predicted series were also calculated in order to identify the best forecasting technique for the data as the model that minimized these forecast indices.

The model of choice was the Holt-Winters Additive model, that was the best forecasting technique among the Exponential smoothing models (MAE = 1.516; MAPE $=4.727)$. This final model was the result of several iterations of the identification, estimation, and checking process, and it met the conventional criteria for the adequacy of the model. The autocorrelation and partial autocorrelation functions of the residuals showed a good fit. The residual plots showed small variations around the zero mean. None of these residuals had its magnitude larger than twice the standard deviation. Residual autocorrelations were not significantly different from zero as a set and had constant variance, thus confirming the adequacy of the model (Ljung-Box statistic $=6.807 ; \mathrm{p}$-value $=0.963)$.

To determine the extent of the impact of policy changes on pharmaceutical utilisation, we used segmented linear regression for the interrupted time-series analysis [34]. This analysis provided estimates of an outcome (DDD/1000 inh. day) before and after defined change points (the introductions of co-payment and the revision of national prescription guidelines). To eliminate the seasonal component related to the consumption of the drug and assess the "true effect" of the above-mentioned measures, we performed a seasonal decomposition on the series before the estimation of the regression model. Segmented linear regression divides a time-series into preand post-intervention segments. In this case, we had two change points at different time periods, so our series was divided into three segments.

The model has two parameters of interest: the level and slope. Therefore the difference between the two segments can be quantified by testing the change in these two parameters. A change in level between the pre- and the post-intervention segments indicates a step-change, and a change in slope indicates a change in trend. The estimated base model is the following:

$$
\begin{aligned}
Y_{t}= & \beta_{0}+\beta_{1} * \text { time }+\beta_{2} * \text { copayment }+\beta_{3} \\
& * \text { time after copayment }+\beta_{4} * \text { reimbursement } \\
& +\beta_{5} * \text { time after reimbursement }+\sum_{i=1}^{16} \beta_{i} * D_{i}+e_{t}
\end{aligned}
$$

Here, $Y_{t}$ is the mean number of DDD/1000 inh. day in month t; time is a continuous variable indicating time in months at time $\mathrm{t}$ from the start of the observation period; co-payment is an indicator for time $t$ occurring before (intervention $=0$ ) or after (intervention $=1$ ) its introduction, which occurred at different instants of time for the considered Italian regions; time after copayment is a continuous variable counting the number of months after the intervention at time $t$, coded 0 before the introduction and 1 (time - time of intervention) after. Reimbursement and time after reimbursement are two variables built in the same mode of the previous ones but refer to the revision of national reimbursement criteria in November, 2004; $e_{t}$ is the error term at time $t$ and represents the random variability not explained by the model. In this model, $\beta_{0}$ estimates the baseline level of the outcome (expressed in DDD/1000 inh. day) per month, at time zero; $\beta_{1}$ estimates the pre-intervention slope (i.e. the baseline trend); $\beta_{2}$ estimates the level change immediately after the introduction of co-payment, that is from the end of the preceding segment; $\beta_{3}$ estimates the change in trend relative to the first intervention compared with the preexisting monthly trend; $\beta_{4}$ and $\beta_{5}$ are respectively the estimate of the level and trend change relative to the revision of AIFA Notes. D represents 17-1 Dummy variables relative to the considered regions. We coded the regional Dummies by the "deviation from means coding" method [35]. This coding expresses effect as the deviation of the "group mean" from the "overall mean". 
We tested whether each of these parameters is significantly different from zero from a two-sided $t$ test to determine whether a discontinuity at each join point existed.

For statistical analysis we used the software SPSS v.13.0 for Windows environment.

\section{Results}

Figure 1 shows the time series of the mean number of statins use (DDD/1000 inh. day) per month, interrupted by the two policy changes: the introduction of copayment in different dates for each regions, indicated by the arrows in the graph, and the revision of AIFA Notes in November 2004, indicated by the vertical line. The visual inspection of the series suggests that the use of statins increased during the study period for both groups of regions.

As shown in Table 1, the consumption of statins increased by 22.9 DDD/1000 inh. day in May 2001 to 54.7 DDD/1000 inh. day in December 2007. On average, there was a $1.7 \%$ increase in statin use each month before the national guideline changed while the increase was about $0.5 \%$ afterwards.

As shown in Figure 2, the revision of AIFA Note 13 was associated with a large change in the use of statins because the observed series is outside the 95\% confidence interval for the short-term forecast. The shortterm forecast beyond the observed series (from May 2001 to November 2004) of statin consumption in all the seventeen regions adequately captured the pattern in the data until the policy change (revision of AIFA Notes) and showed an increasing tendency of drug use with a mean 9.7 DDD/1000 inh. day each month over the observed series during the forecast interval (post intervention period).
This result was confirmed by the estimates of the regression model that explained the effect of policy change. Table 2 contains the parameter estimates from the linear segmented regression model.

The introduction of co-payment was associated with a significant change in slope so that the overall use of the drug increased by 0.04 (95\% CI 0.02 to 0.07 , p-value < 0.001) DDD/1000 inh. day per month in the postintervention period, but there was no evidence of a change in level ( $\mathrm{p}$-value $=0.163$ ).

Prescription guidelines showed a large impact on the use of statins. A temporal association between the revision of the AIFA Note in November 2004 and a remarkable reduction in the upward trend of statin use in the same period were observed. This intervention was associated with a significant decrease in level (coefficient $=-2.80,95 \% \mathrm{CI}-3.70$ to $-1.90 \mathrm{p}$-value $<0.001)$ and slope (coefficient $=-0.33,95 \% \mathrm{CI}-0.37$ to -0.29 p-value $<0.001)$.

\section{Discussion}

This study showed that the change in the national reimbursement criteria influenced the utilization of statins in Italy, determining a statistically significant reduction in the upward trend of prescriptions. On the other hand, the effect of the local co-payment on statin use was negligible. Overall, statin consumption increased from 2001 to 2007, according to previous research showing a similar trend in most European countries [36].

Reimbursement criteria revision that occurred in Italy in 2004 was issued with the aim to improve the appropriateness of drug prescriptions, following updated scientific evidence related to cardiovascular disease risk reduction. Our findings are consistent with Trifirò et al. [37] that reported a significant decrease in the utilization

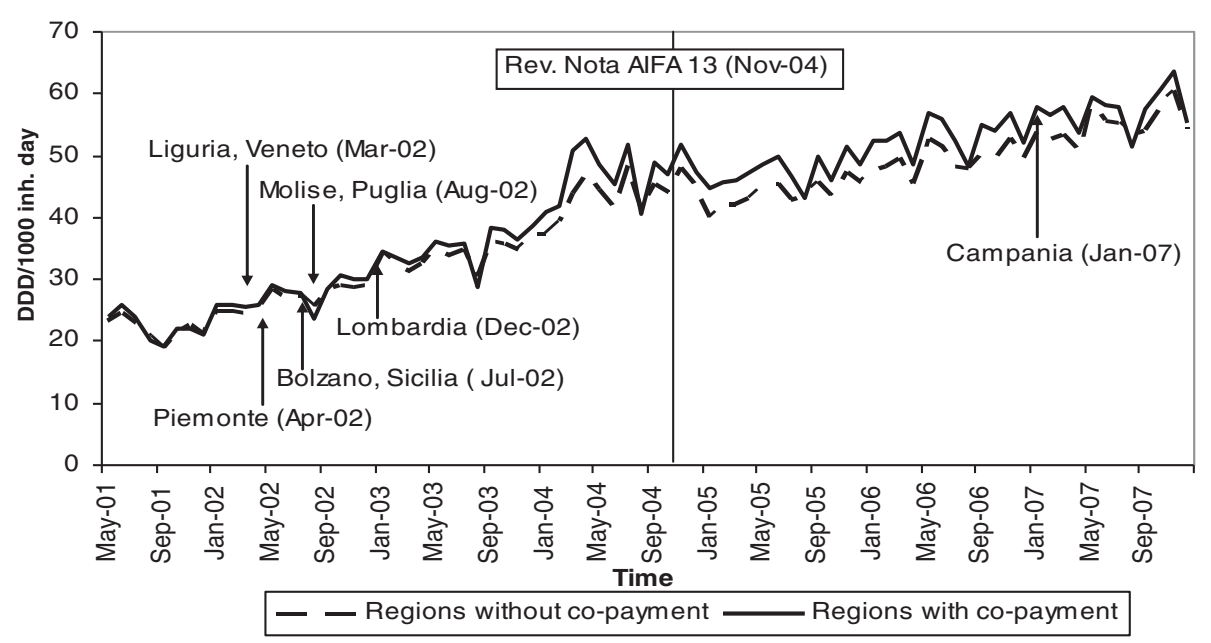

Figure 1 Monthly statins consumption (DDD/1000 inh. day) in the two groups of regions. The arrows show the month and the year in which the indicated regions have applied the co-payment measures. 
Table 1 Statins consumption per 1000 inhabitants per month in the considered Italian regions

\begin{tabular}{|c|c|c|c|c|c|c|}
\hline & Regions & May-01 & Nov-04 & Dec-07 & $\Delta \%(04-01) *$ & $\Delta \%(07-04) *$ \\
\hline \multirow{9}{*}{ Regions with the co-payment } & P.A. Bolzano & 23.83 & 40.25 & 42.99 & 1.26 & 0.17 \\
\hline & Campania & 26.23 & 54.00 & 61.32 & 1.73 & 0.33 \\
\hline & Liguria & 13.93 & 47.27 & 52.91 & 2.95 & 0.29 \\
\hline & Lombardia & 27.29 & 48.81 & 55.83 & 1.39 & 0.35 \\
\hline & Molise & 17.53 & 39.79 & 45.40 & 1.97 & 0.34 \\
\hline & Piemonte & 23.90 & 39.62 & 47.74 & 1.21 & 0.48 \\
\hline & Puglia & 21.61 & 47.06 & 63.55 & 1.87 & 0.77 \\
\hline & Sicilia & 25.89 & 55.91 & 66.84 & 1.85 & 0.46 \\
\hline & Veneto & 26.61 & 48.06 & 59.69 & 1.42 & 0.56 \\
\hline Total Regions with co-payment: & & 22.98 & 46.75 & 55.14 & 1.74 & 0.42 \\
\hline \multirow{8}{*}{ Regions without co-payment } & Basilicata & 20.93 & 50.00 & 58.43 & 2.10 & 0.40 \\
\hline & Emilia-Romagna & 27.01 & 50.10 & 61.66 & 1.48 & 0.53 \\
\hline & Friuli Venezia Giulia & 26.57 & 47.72 & 57.11 & 1.40 & 0.46 \\
\hline & Marche & 21.38 & 45.47 & 62.00 & 1.81 & 0.80 \\
\hline & Toscana & 21.60 & 38.21 & 49.24 & 1.37 & 0.65 \\
\hline & P.A. Trento & 24.80 & 41.27 & 53.58 & 1.22 & 0.67 \\
\hline & Umbria & 19.16 & 39.83 & 50.50 & 1.76 & 0.61 \\
\hline & Valle d'Aosta & 21.46 & 40.73 & 41.86 & 1.54 & 0.07 \\
\hline Total Regions without co-payment: & & 22.86 & 44.17 & 54.30 & 1.58 & 0.52 \\
\hline Total: & & 22.93 & 45.54 & 54.74 & 1.67 & 0.47 \\
\hline
\end{tabular}

Comparison May, 2001- November, 2004 and November, 2004- December, 2007.

*Average monthly variation index.

of statin after the Nota 13 change in a general practice in southern Italy. An increased consumption was found only for diabetic patients, which was probably related to the extended criteria of reimbursement for secondary prevention. On the contrary, a study conducted in
Austria by Winkelmayer et al. [15], showed that national change in statin prescribing policies from secondary to primary prevention among diabetic patients did not affect the overall trend of statin use. Northern Europe brings instead some examples of how policies that limit

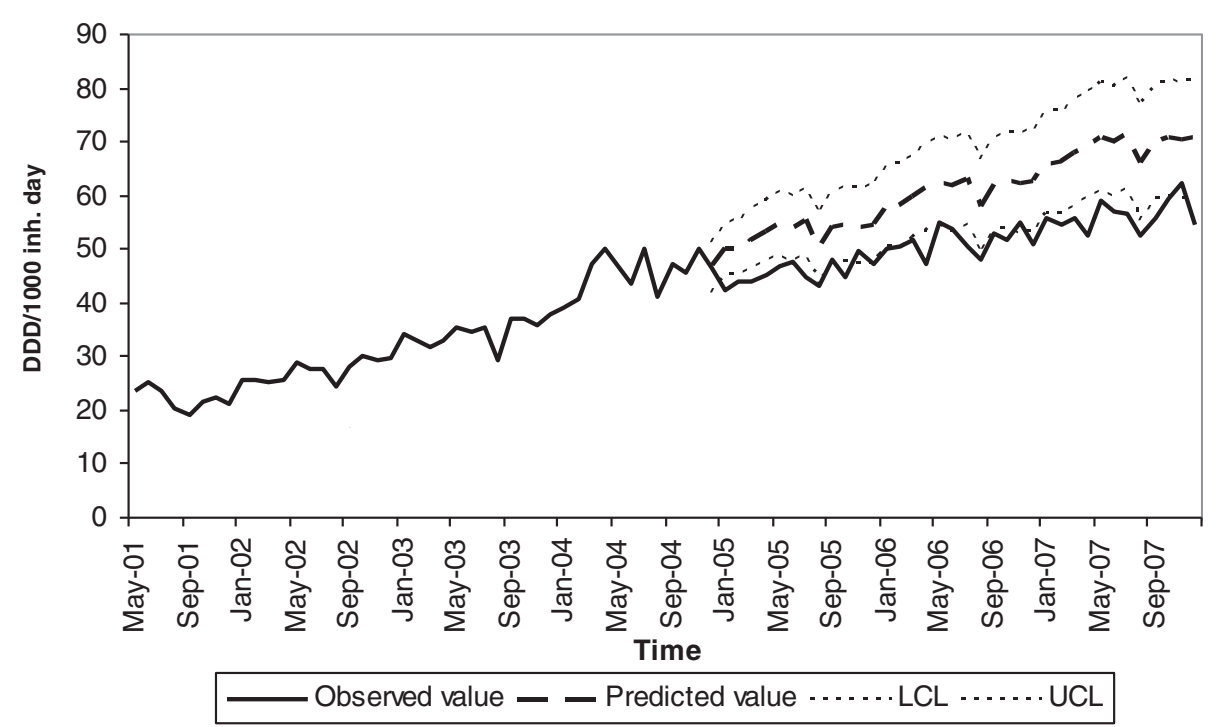

Figure 2 Monthly statins consumption (DDD/1000 inh. day) in the two groups of regions. Observed vs predicted. The figure shows observed vs predicted series after the change of the reimbursement criteria in November 2004. Lower and upper confidence level are set at $95 \%$. 
Table 2 Model parameter estimates, standard errors and p-values of statins consumption

\begin{tabular}{lcccc}
\hline Model & Coefficients & p-value & \multicolumn{2}{c}{ 95\% Conf. interval } \\
\cline { 3 - 5 } & B & & Lower & Upper \\
\hline (Constant) & 18.06 & $<0.001$ & 17.43 & 0.65 \\
time & 0.68 & $<0.001$ & -1.88 & 0.71 \\
Co-payment & -0.78 & 0.163 & 0.32 \\
Time after co-payment & 0.04 & $<0.001$ & -3.70 & -0.07 \\
Reimbursement criteria change & -2.80 & $<0.001$ & -0.37 & -0.29 \\
Time after reimbursement criteria change & -0.33 & $<0.001$ & & \\
\hline
\end{tabular}

the reimbursement of drugs can be a powerful tool for changing the use of medication. A Norwegian study, conducted in 2007 [14], showed an increase in the consumption of statins and, simultaneously, a decrease of the expenditure after initiating an intervention that forced physicians to prescribe simvastatin or an alternative and to carefully explain the need to use a different statin. Such a policy caused an increase in prescriptions of the less costly statins and an increase in consumption by first-time users while physicians continued to preserve the adherence to the therapy. Similar results came from Finland [16] that reduced costs by instituting policies promoting use of less expensive statins and restricting reimbursement of the more expensive atorvastatin, whose patent expired only in late 2011 [38].

Authors from Harvard and Canada [39] recently applied the interrupted time series study design to assess the impact of the prior authorization (a prescribing-limitation policy that allows the prescription of a non-preferred medication only after the approval from Medicaid) with contrasting results for the two groups regarding the consumption of statins. The policy was associated with a lower use of statins in Michigan, but the effect was negligible in Indiana where there had been little use of nonpreferred medications before the policy was implemented.

In our study, the impact of the co-payment on the consumption trend of statins increased statin use in a statistically significant way, but its real effect was very small, as shown in Table 2. Some authors stressed the fact that the main purpose of cost sharing is to introduce incentives so that patients would be able to compare cost to expected outcomes [40]. In Italy, however, the cost shared by the patient is fixed and not proportional as in other countries such as USA or Canada [19]; therefore, this measure becomes irrelevant to a price-oriented behaviour by the consumer. Consequently, it becomes a mere cost-containment tool in the short run [29]. This could conceal some implications for the safety of the population, possibly modifying the adherence to treatment [41-43].
Indeed, Gibson [17] found that as statin cost-sharing levels increase, adherence to statin treatment falls. This could lead to health risks, increasing access to health services and eventually to an increase in expenditure $[1,44,45]$.

\section{Limitations and strengths}

Unfortunately, aggregated data do not allow us to collect information about clinical outcomes. For this reason, we cannot assess the appropriateness in the prescription and the adherence to the therapy. As a second limitation, we did not consider the generic market, the marketing strategies such as incentives offered to general practitioners, or the regional policies (e.g., limit on the number of prescriptions for recipe) that may have had an impact on the consumption of statins. A third limitation resides on the observational nature of this study, which does not allow establishing a causal relationship between the intervention and the change in the consumption trend of statins.

However, we would like to highlight the strengths of this study. We could rely on a large dataset covering the entire national territory for a 7-year period. The data are weighted by gender and age, allowing us to overcome differences in the demographic structure among regions. Furthermore, the interrupted time series regression analysis allowed us to obtain more valid estimates of the impact of co-payment and national reimbursement criteria on the utilization of statins compared to a prepost design $[1,34,46]$.

\section{Conclusions}

Consumption of statins in Italy increased almost threefold during the study period. Interventions at the central level (modification of reimbursement criteria) had an impact in mitigating the growth, showing a temporal association with an immediate drop and a decrease in trend of statin use, while the regional policies (copayment) were associated with a small increase in trend of statin use. In a heavily regulated market, efforts for decentralisation should be aimed at gaining better control over the consumption of statins at the regional level. 


\section{Competing interests}

The authors declare that there was no financial relationships with any organizations that might have an interest in the submitted work; no other relationships or activities that could appear to have influenced the submitted work.

\section{Authors' contributions}

GD \& BF conceived of the study and participated in its design, PN \& WR coordinated the study and revised it, AA participated in its design and performed the statistical analysis, LI carried out literature search and drafted the manuscript, CBNAB \& GS helped to draft the manuscript and contributed to the interpretation of data, RDC \& RR collected data and revised the draft. All authors read and approved the final manuscript.

\section{Acknowledgements}

This paper was supported by Faculty Research Fund, Catholic University of the Sacred Heart (Italy), under the title project "Drug utilization and Institutional regulation" (2011).

\section{Author details}

${ }^{1}$ Department of Public Health, Catholic University of the Sacred Heart, Rome, Italy. ${ }^{2}$ Department of Human Sciences, Society and Health, University of Cassino and Southern Lazio, Cassino, Italy. ${ }^{3}$ Department of Pharmacology, Catholic University of the Sacred Heart, Rome, Italy. ${ }^{4}$ National Institute of Health, Rome, Italy.

Received: 19 July 2013 Accepted: 2 January 2014

Published: 6 January 2014

\section{References}

1. Austvoll-Dahlgren A, Aaserud M, Vist G, Ramsay C, Oxman AD, Sturm H, Kösters JP, Vernby A: Pharmaceutical policies: effects of cap and co-payment on rational drug use. Cochrane Database Syst Rev 2008, 23(1):CD007017.

2. Ess SM, Schneeweiss S, Szucs TD: European healthcare policies for controlling drug expenditure. (Review). Pharmacoeconomics 2003, 21(2):89-103.

3. Gotto AM, Grundy SM: Lowering LDL cholesterol: questions from recent meta-analyses and subset analyses of clinical trial data issues from the Interdisciplinary Council on Reducing the Risk for Coronary Heart Disease, 9th Council Meeting. Circulation 1999, 99:E1-E7.

4. Hebert PR, Gaziano JM, Chan KS, Hennekens CH: Cholesterol lowering with statin drugs, risk of stroke, and total mortality. An overview of randomized trials. JAMA 1997, 278:313-321.

5. Sever PS, Dahlof B, Poulter NR, Wedel H, Beevers G, Caulfield M, Collins R, Kjeldsen SE, Kristinsson A, McInnes GT, Mehlsen J, Nieminen M, O'Brien E, Ostergren J, ASCOT investigators: Prevention of coronary and stroke events with atorvastatin in hypertensive patients who have average or lower-than-average cholesterol concentrations, in the Anglo-Scandinavian Cardiac Outcomes Trial-Lipid Lowering Arm (ASCOT-LLA): a multicentre randomised controlled trial. Lancet 2003, 361:1149-1158.

6. Eussen SR, van der Elst ME, Klungel OH, Rompelberg CJ, Garssen J, Oosterveld MH, de Boer A, de Gier JJ, Bouvy ML: A pharmaceutical care program to improve adherence to statin therapy: a randomized controlled trial. Ann Pharmacother 2010, 44(12):1905-1913.

7. Lingsma HF, Steyerberg EW, op Reimer WJ S, van Domburg R, Dippel DW, Netherlands Stroke Survey Investigators: Statin treatment after a recent TIA or stroke: is effectiveness shown in randomized clinical trials also observed in everyday clinical practice? Acta Neuro/ Scand 2010, 122(1):15-20.

8. Pedersen TR, Kjekshus J, Berg K, Haghfelt T, Faergeman O, Faergeman G, Pyörälä K, Miettinen T, Wilhelmsen L, Olsson AG, Wedel H, Scandinavian Simvastatin Survival Study Group: Randomised trial of cholesterol lowering in 4444 patients with coronary heart disease: the Scandinavian Simvastatin Survival Study (4S). Lancet 1994, 344(8934):1383-1389.

9. Colhoun HM, Betteridge DJ, Durrington PN, Hitman GA, Neil HA Livingstone SJ, Thomason MJ, Mackness MI, Charlton-Menys V, Fuller JH, CARDS investigators: Primary prevention of cardiovascular disease with atorvastatin in type 2 diabetes in the Collaborative Atorvastatin Diabetes Study (CARDS): multicentre randomised placebo-controlled trial. Lancet 2004, 364(9435):685-696.
10. Penning-van Beest FJ, Termorshuizen F, Goettsch WG, Klungel OH, Kastelein JJ, Herings RM: Adherence to evidence-based statin guidelines reduces the risk of hospitalizations for acute myocardial infarction by $40 \%$ : a cohort study. Eur Heart J 2007, 28(2):154-159.

11. Ali R, Alexander KP: Statins for the primary prevention of cardiovascular events in older adults: a review of the evidence. Am J Geriatr Pharmacother 2007, 5(1):52-63.

12. Ong HT: The statin studies: from targeting hypercholesterolaemia to targeting the high-risk patient. QJM 2005, 98(8):599-614

13. Puig-Junoy J: What is required to evaluate the impact of pharmaceutical reference pricing? Appl Health Econ Health Policy 2005, 4(2):87-98.

14. Sakshaug S, Furu K, Karlstad $\varnothing$, Rønning M, Skurtveit S: Switching statins in Norway after new reimbursement policy - a nationwide prescription study. Br J Clin Pharmacol 2007, 64:476-481.

15. Winkelmayer WC, Asslaber M, Bucsics A, Burkhardt T, Schautzer A, Wieninger $P$, Pogantsch M, Brookhart MA, Pharmacoeconomics Advisory Council of the Austrian Sickness Funds: Impact of reimbursement changes on statin use among patients with diabetes in Austria. Wien Klin Wochenschr 2010, 122(3-4):89-94.

16. Martikainen JE, Saastamoinen LK, Korhonen MJ, Enlund H, Helin-Salmivaara A: Impact of restricted reimbursement on the use of statins in Finland a register-based study. Med Care 2010, 48(9):761-766.

17. Gibson TB, Mark TL, Axelsen K, Baser O, Rublee DA, McGuigan KA: Impact of statin copayments on adherence and medical care utilization and expenditure. Am J Manag Care 2006, 12:SP11-SP19.

18. Pilote $L$, Beck C, Richard H, Eisenberg MJ: The effects of cost-sharing on essential drug prescriptions, utilization of medical care and outcomes after acute myocardial infarction in elderly patients. CMAJ 2002, 167(3):246-252.

19. Schneeweiss S, Patrick AR, Maclure M, Dormuth CR, Glynn RJ: Adherence to statin therapy under drug cost sharing in patients with and without acute myocardial infarction: a population-based natural experiment. Circulation 2007, 115(16):2128-2135.

20. Dickinson M, Jacobzone S: Pharmaceutical use and expenditure for cardiovascular disease and stroke: a study of 12 OECD countries. OECD Health Working Papers, No. 1, OECD Publishing; 2003. http://dx.doi.org/10.1787/ 237273475872

21. Gruppo di lavoro OsMed: L'uso dei farmaci in Italia. Rapporto nazionale anno 2000. Roma: II Pensiero Scientifico Editore; 2001 [OsMed Working Team. The drug utilisation in Italy, National Reports 2000].

22. Gruppo di lavoro OsMed: L'uso dei farmaci in Italia. Rapporto nazionale anno 2010. Roma: II Pensiero Scientifico Editore; 2011 [OsMed Working Team. The drug utilisation in Italy, National Reports 2011].

23. Gruppo di lavoro OsMed: L'uso dei farmaci in Italia. Rapporto nazionale anno 2011. Roma: II Pensiero Scientifico Editore; 2012 [OsMed Working Team. The drug utilisation in Italy, National Reports 2012]

24. Ghislandi S, Krulichova I, Garattini L: Pharmaceutical policy in Italy: towards a structural change? Health Policy 2005, 72:53-63.

25. Torbica A, Fattore G: The "Essential Levels of Care" in Italy: when being explicit serves the devolution of powers. Eur J Health Econ 2005, 6(Suppl 1):46-52.

26. Mapelli V, Lucioni C: Spending on pharmaceuticals in Italy: macro constraints with local autonomy. Value Health 2003, 6(Suppl 1):S31-S45.

27. Fiorio CV, Siciliani L: Co-payments and the demand for pharmaceuticals: evidence from Italy. Econ Model 2010, 27:835-841.

28. Agenzia Nazionale del Farmaco (AIFA). Note AIFA. http://www. agenziafarmaco.gov.it/it/content/note-aifa.

29. Fattore $G$, Jommi C: The last decade of Italian pharmaceutical policy: instability or consolidation? Pharmacoeconomics 2008, 26(1):5-15.

30. Gruppo di lavoro OsMed: In L'uso dei farmaci in Italia. Rapporto nazionale anno 2004. Edited by II Pensiero Scientifico. Roma: OsMed Working Team. The drug utilisation in Italy, National Reports 2005; 2005.

31. Ferrario M, Chiodini P, Chambless LE, Cesana G, Vanuzzo D, Panico S, Sega R, Pilotto L, Palmieri L, Giampaoli S, CUORE Project Research Group: Prediction of coronary events in a low incidence population. Assesing accurancy of CUORE Cohort Study prediction equation. Int J Epidemiol 2005, 34(2):413-421.

32. ATC/DDD Index 2013. http://www.whocc.no/atc ddd index/

33. Yaffee RA, McGee M: An introduction to time series analysis and forecasting: with applications of SAS ${ }^{\circledR}$ and SPSS ${ }^{\circledR}$. New York: Academic Press; 2000.

34. Wagner AK, Soumerai SB, Zhang F, Ross-Degnan D: Segmented regression analysis of interrupted time series studies in medication use research. J Clin Pharm Ther 2002, 27(4):299-309. 
35. Hosmer W, Lemeshow S: Applied Logistic Regression. 2nd edition. New York: Wiley; 2000.

36. Walley T, Folino-Gallo P, Stephens P, Van Ganse E: Trends in prescribing and utilization of statins and other lipid lowering drugs across Europe 1997-2003. Br J Clin Pharmacol 2005, 60:543-551.

37. Trifirò G, Alaqua M, Corrao S, Moretti S, Tari DU, Galdo M, UVEC Group, Caputi AP, Arcoraci V: Lipid-lowering drug use in Italian primary care: effects of reimbursement criteria revision. Eur J Clin Pharmacol 2008, 64(6):619-625.

38. IMS Health, MIDAS, Dec 2011. http://www.imshealth.com/ims/Global/ Content/Insights/MS\%20Institute\%20for\%20Healthcare\%20Informatics/ IHII_Medicines_in_U.S_Report_2011.pdf.

39. Lu CY, Law MR, Soumerai SB, Graves AJ, LeCates RF, Zhang F, Ross-Degnan $D$, Adams AS: Impact of prior authorization on the use and costs of lipid-lowering medications among Michigan and Indiana dual enrollees in Medicaid and Medicare: results of a longitudinal, population-based study. Clin Ther 2011, 33(1):135-144.

40. Smith DG: The effects of copayments and generic substitution on the use and costs of prescription drugs. Inquiry 1993, 30(2):189-198.

41. Poluzzi E, Strahinja P, Lanzoni M, Vargiu A, Silvani MC, Motola D, Gaddi A, Vaccheri A, Montanaro N: Adherence to statin therapy and patients' cardiovascular risk: a pharmacoepidemiological study in Italy. Eur J Clin Pharmacol 2008, 64:425-432.

42. Lucioni C, Mazzi S, Cerra C, Lottaroli S, Dellagiovanna M, Fratino P: Uno studio di drug utilisation delle statine nella recente prassi terapeutica italiana. Pharmacoeconomics 2006, 8(1):3-17.

43. Peterson AM, McGhan WF: Pharmacoeconomic impact of non-compliance with statins. Pharmacoeconomics 2005, 23(1):13-25.

44. Goldman DP, Joyce GF, Zheng Y: Prescription drug cost sharing: associations with medication and medical utilization and spending and health. JAMA 2007, 298(1):61-69.

45. Li X, Guh D, Lacaille D, Esdaile J, Anis AH: The impact of cost sharing of prescription drug expenditures on health care utilization by the elderly: own- and cross-price elasticities. Health Policy 2007, 82(3):340-347.

46. Damiani G, Federico B, Silvestrini G, Bianchi CB, Anselmi A, lodice L, Ronconi A, Navarra P, Da Cas R, Raschetti R, Ricciardi W: Impact of regional copayment policy on selective serotonin reuptake inhibitor (SSRI) consumption and expenditure in Italy. Eur J Clin Pharmacol 2013, 69(4):957-963.

doi:10.1186/1472-6963-14-6

Cite this article as: Damiani et al:: The impact of Regional co-payment and National reimbursement criteria on statins use in Italy: an interrupted time-series analysis. BMC Health Services Research 2014 14:6.

\section{Submit your next manuscript to BioMed Central and take full advantage of:}

- Convenient online submission

- Thorough peer review

- No space constraints or color figure charges

- Immediate publication on acceptance

- Inclusion in PubMed, CAS, Scopus and Google Scholar

- Research which is freely available for redistribution

Submit your manuscript at www.biomedcentral.com/submit 